\title{
AS EXPORTAÇÕES BRASILEIRAS DE MANUFATURADOS DE MADEIRA
}

\author{
BRAZILIAN EXPORTS OF MANUFACTURED WOOD
}

\author{
Rafael de Azevedo Calderon ${ }^{1}$ Humberto Ângelo ${ }^{2}$
}

RESUMO

O presente trabalho trata das exportações brasileiras de madeira serrada de não coníferas, laminados e compensados durante o período de 1961 a 2002. Os dados referentes aos três produtos estudados foram agregados pelo método de Fisher para que pudesse ser feita uma avaliação econométrica do mercado dos três produtos. Foram especificados modelos de oferta e demanda das exportações brasileiras e estas estimados pelo método de Mínimos Quadrados Ordinários (MQO). Os resultados foram satisfatórios e condizem com a literatura. A oferta de exportações apresentou uma resposta positiva em relação à remuneração do exportador, à produção, à utilização da capacidade instalada e à tendência, e negativo em relação à demanda interna. A demanda pelas exportações brasileiras foi positivamente influenciada pela renda mundial, índice de participação e tendência, e negativamente pelo preço relativo. A baixa elasticidade-preço da demanda encontrada pode ter implicações na conservação dos recursos florestais brasileiros, pois os exportadores poderão aumentar os preços, diminuir as quantidades e ainda terem um aumento das receitas.

Palavras-chave: exportações; manufaturados de madeira; econometria.

\section{ABSTRACT}

The present work deals with the Brazilian exports of sawnwood of non-coniferous, veneer sheets and plywood, from 1961 to 2002. The data regarding the three studied products, sawnwood of nonconiferous, veneer sheets and plywood, were joined through the method of Fisher so that an econometric evaluation of the market of the three products could be carried out. Supply and demand models of the Brazilian exports were specified. The results were satisfactory and they match with the literature. The supply of exports presented a positive answer in relation to the exporter's remuneration, to the production, to the use of the installed capacity (cycles of domestic economical activity) and to the tendency, and negative in relation to the internal demand. The demand for the Brazilian exports was influenced positively by the world income, participation index and tendency, and negatively for the relative price. The low elasticity-price of the found demand can have implications in the conservation of the Brazilian forest resources because the exporters can increase the prices, reduce the amounts and still increase the incomes.

Key words: exports; manufactured wood; econometrics.

\section{INTRODUÇÃO}

O Brasil produziu em 2002 114,6 bilhões de metros cúbicos em produtos florestais. De 1992 a 2002, as nossas exportações passaram de US\$ 1,9 bilhões para US\$ 2,6 bilhões. Somos o segundo país em produção de madeira serrada de não-coníferas e o quinto na produção de compensados. As exportações brasileiras de madeiras serradas, compensados e laminados chegaram a pouco mais de US\$ 756,8 milhões em 2002, contra os US\$343,7 milhões em 1992; ou seja, um aumento de 120\% em dez anos (FAO, 2004).

Para que seja possível o planejamento da utilização dos estoques naturais de madeira, e a sua utilização de forma sustentável, sem comprometer as necessidades de produção no futuro, é imprescindível a existência de estudos que forneçam informações para a predição dos efeitos que as alterações nas variáveis econômicas nacionais e internacionais terão na oferta e na demandas dos produtos florestais brasileiros.

Este trabalho visa a contribuir com informações sobre a demanda e oferta do agregado composto por madeira serrada de não-coníferas, laminados e compensados, produzidos no Brasil e exportados. Mais especificamente, busca especificar funções de oferta e demanda para as exportações brasileiras e determinar as elasticidades das variáveis que afetam as exportações brasileiras do agregado.

Essas informações visam a responder questões relativas ao comércio desses produtos tais como:

1. Engenheiro Florestal, Mestrando em Ciências Florestais pela Universidade de Brasília, Caixa Postal 04357, CEP 70919-970 Brasília (DF).

2. Engenheiro Florestal, Dr., Professor do Departamento de Engenharia Florestal, Universidade de Brasília, Caixa Postal 04357, CEP 70919-970 Brasília (DF). humb@unb.br

Recebido para publicação em 26/04/2005 e aceito em 3/02/2006. 
Quanto uma mudança nas tarifas e subsídios iria modificar o saldo comercial de produtos florestais brasileiros? Com que amplitude o aumento da capacidade instalada do setor afetaria as exportações brasileiras de produtos florestais? Mudanças na renda doméstica e internacional afetam as exportações brasileiras de produtos florestais? Qual é o efeito que mudanças de preço nos produtos florestais brasileiros trariam para as exportações? Mudanças nos preços internacionais influenciariam as nossas exportações de madeiras tropicais, laminados e compensados?

\section{MATERIAIS E MÉTODO}

Os produtos, objeto deste estudo, foram às madeiras serradas de não-coníferas, laminados e compensados exportados pelo Brasil no período de 1961 a 2002.

Foram consideradas como não coníferas, para este trabalho, as madeiras classificadas pela Food and Agriculture Organization of the United Nations (FAO) como "Non-Coniferous (NC)" não-coníferas, que são todas as espécies classificadas botanicamente como angiospermas, folhosas "broadleaved" ou madeira dura "hardwoods".

A teoria que mais se ajusta ao mercado florestal brasileiro considera um modelo em que o preço e a quantidade exportada são determinados simultaneamente pela interação de funções de oferta e demanda com elasticidades-preço finitas (BRASIL, 2002; Raimundo, 2001; Ângelo e Silva, 1998; Ângelo et al., 1998).

\section{Função de oferta}

A função de oferta adotada neste trabalho está na forma log-linear e é descrita a seguir:

$\ln Q_{t}^{O}=\alpha_{0}+\alpha_{1} \ln R E M+\alpha_{2} \ln P R O_{t}+\alpha_{3} \ln D_{t}+\alpha_{4} \ln U_{t}+\alpha_{5} \ln T_{t}+\varepsilon_{1}$

Em que:

$Q^{O}=$ índice de quantidade dos produtos oferecidos para exportação; $R E M=$ remuneração do exportador $=$ $\frac{P \times T C}{I P D} ; P=$ índice do preço FOB deflacionado das exportações; $T C=$ taxa nominal de câmbio, em moeda nacional por dólares; $I P D=$ índice de preço doméstico; $P R O=$ produção; $D=$ demanda interna; $U=$ utilização da capacidade instalada industrial; $T=$ tendência; $\varepsilon_{1}=$ termo estocástico.

A elevação dos preços para exportação, em moeda nacional, em relação aos preços internos, aumenta a remuneração relativa do exportador; induzindo a um aumento das vendas externas. Ou seja, as exportações dependem positivamente do preço relativo $P R$, (Ângelo et al., 1998 e Zini Jr., 1988). O IPD afeta a função de duas formas, a primeira é servindo de proxy dos custos de produção, quanto mais o IPD sobe, menor a margem de lucro. A segunda é alterando a vantagem relativa de se exportar, quanto maior o IPD, mais vantajoso é vender no mercado interno, diminuindo a oferta para exportação.

A variável utilização da capacidade instalada $(U)$ é utilizada para identificar o efeito dos ciclos da economia nacional sobre a oferta de madeiras para exportação. Segundo Zini Jr. (1988), o valor do coeficiente dessa variável pode indicar um viés pró ou anticomércio. Um valor maior que a unidade indica um viés pró-comércio; um valor unitário indica neutralidade; menor que um indica anticomércio e um valor negativo indica um viés anticomércio forte.

Uma das vantagens da especificação logarítmica da função é que as elasticidades são dadas diretamente pelos valores de $\alpha_{i}$. Os valores esperados para os coeficientes $\alpha_{1}, \alpha_{2}, \alpha_{4}, \alpha_{5}$ é positivo e para $\alpha_{3}$ negativo.

\section{Função de demanda}

A função de demanda foi especificada da seguinte forma:

$$
\ln Q_{t}^{D}=\beta_{0}+\beta_{1} \ln P R_{t}+\beta_{2} \ln R W_{t}+\beta_{3} \ln I P+\beta_{4} \ln T_{t}+\varepsilon_{2}
$$

Em que: $Q^{D}=$ índice de quantidade de produtos demandados pela exportação; $P R=$ preço relativo $=P / P W$; $P=$ preço FOB do agregado brasileiro; $P W=$ preço FOB do substituto; $R W=$ renda dos países importadores; $I P=$ índice de participação; $T=$ tendência; $\varepsilon_{2}=$ termo estocástico.

Neste modelo, a demanda depende negativamente do preço relativo $(P R)$ e positivamente da renda 
dos paises importadores $(R W)$ e do índice de participação $(I P)$, o sinal do coeficiente da variável tendência não é conhecido a princípio, mas segundo Ângelo et al. (1998) ela tenta captar os deslocamentos da curva de demanda e os efeitos de fatores como a mudança na distribuição da renda, nos gostos e preferências dos consumidores.

Para a construção da variável preço relativo $(P R)$, utilizaram-se os preços das exportações mundiais de madeira serrada de não-coníferas, laminados e compensados, como os produtos substitutos dos produtos nacionais.

As equações [1] e [2] foram estimadas utilizando-se o método de mínimos quadrados ordinários (MQO) utilizado em conjunto com o método de Cocrane e Orcut (1949), citado por Gujarati (2000), para correção da correlação serial dos resíduos.

O software utilizado para estimar as regressões de oferta e demanda foi o $\operatorname{SPSS}^{1} 12.0$ para Windows.

\section{Avaliação dos modelos}

Além de avaliar os valores assumidos pelo coeficiente de determinação $\left(\mathrm{R}^{2}\right)$ e pelas estatísticas " $F$ " de significância global da regressão e " $t$ " de significância dos coeficientes parciais, também será utilizado o teste " $d$ " de Durbin e Watson, para testar a presença de auto-correlação serial dos resíduos.

\section{Dados utilizados}

As variáveis incluídas neste trabalho foram:

Índice das quantidades exportadas pelo Brasil de madeira serrada de não-coníferas, laminados e compensados (Q). Calculado partindo dos preços e quantidades exportadas pelo Brasil de madeira serrada de não coníferas, laminados e compensados. As séries utilizadas são as da FAO (2004), tendo como base o ano 2000 .

Índice dos preços das exportações brasileiras de madeira serrada de não-coníferas, laminados e compensados (P ). Calculado partindo dos preços e quantidades exportadas pelo Brasil de madeira serrada de não coníferas, laminados e compensados. As séries utilizadas são as da FAO (2004) tendo como base o ano 2000 .

Taxa nominal de câmbio (TC), em moeda nacional por dólares, calculada pelo Banco Central do Brasil e disponível no IPEADATA (2004).

Índice de preço doméstico (IPD). Índice utilizado para medir as variações dos custos de produção brasileiros. A série utilizada foi o Índice Geral de Preços, disponibilidade interna (IGP-DI), disponível no IPEADATA (2004).

Remuneração real do exportador (REM), calculado pela fórmula $(P \times T C) / I P D$, mede alem das variações de preço e câmbio, as variações nos custos de produção brasileiros pela utilização do IGP-DI, como índice de preços doméstico.

Índice de utilização da capacidade instalada da indústria (U). Mede os níveis de atividade industrial brasileira, é também conhecida como variável cíclica, pois mede os ciclos de aquecimento da economia nacional, corresponde à razão entre o produto interno bruto efetivo e o produto interno potencial. A série utilizada é encontrada em Raimundo (2001), os anos de 2000, 2001 e 2002 foram calculados com base na variável uso da capacidade instalada, calculada pela Fundação Getúlio Vargas (FGV) e disponível em IPEADATA (2004).

Demanda interna (D). Mede a taxa de consumo em relação à produção, é calculada pelo quociente entre a quantidade consumida e produzida de madeira serrada de não-coníferas, compensados e laminados. É a média geométrica dos relativos de consumo/produção de cada um dos produtos.

Índice de preços das exportações mundiais de madeira serrada de não-coníferas, laminados e compensados (PW). Calculado partindo dos preços e quantidades exportadas pelo mundo. As séries

\footnotetext{
${ }^{1}$ SPSS Inc., 444 N. Michigan Ave., Chicago, IL 60611. (312) 329-3600. (Estados Unidos).
} 
utilizadas são as da FAO (2004) tendo como base o ano 2000.

Renda dos países importadores, calculada partindo do valor das exportações mundiais de madeira serrada de não coníferas, laminados e compensados (RW). Ano $2000=100$. Os dados são da FAO (2004).

Índice de produção brasileira (PRO). É calculado pela média das quantidades produzidas relativas de madeira serrada de não-coníferas, laminados e compensados. Ano $200=100$. Dados da FAO (2004).

Índice de participação na produção (IP). Índice que mede a participação em porcentagem, do Brasil em relação ao mundo, como produtor de madeira serrada de não-coníferas, laminados e compensados, em termos de volume. É a média das participações relativas de cada um dos produtos estudados no trabalho. Dados da FAO (2004).

Tendência (T). Série construída como mostraram Wyzykowski e Almeida (2002), $T_{1961}=1, T_{1962}$ $=2, \ldots, \mathrm{T}_{2002}=42$. Variável utilizada para medir as tendências que afetaram a oferta e/ou a demanda.

Neste estudo, as quantidades e preços da madeira serrada de não-coníferas (NC), compensados e laminados são sempre tratadas em forma de índice, que agrega os valores referentes aos três produtos.

\section{RESULTADOS E DISCUSSÃO}

Aqui são apresentados os resultados das regressões estimadas para a oferta e demanda por exportações brasileiras do agregado.

\section{Oferta}

A regressão ajustada apresentou um bom poder explicativo, representado pelo alto valor do coeficiente de determinação $\mathrm{R}^{2}$, que mostra um poder explicativo das variáveis independentes de $98 \%$ sobre a oferta para exportação. O teste $F$, de significância global da regressão foi significativo a $1 \%$ de probabilidade. Todos os coeficientes apresentaram os sinais esperados pela teoria econômica e pela literatura.

TABELA 1: Estimativa da equação de oferta para as exportações brasileiras de manufaturados de madeira, com dados anuais, no período de 1961 a 2002.

TABLE 1: Estimate of supply equation for the Brazilian exports of manufactured wood, with annual data, from 1961 to 2002 .

\begin{tabular}{cc|c|c|c|c|c|c|c|c}
\hline & Constante & REM & PRO & U & D & T & $\mathrm{R}^{2}$ & F & DW \\
\hline Coeficiente & $-0,013$ & 0,217 & 0,927 & 0,514 & $-1,202$ & 0,712 & 0,98 & $336,07^{*}$ & 0,87 \\
\hline$T$ & $-0,006^{\text {ns }}$ & $1,889^{* *}$ & $4,619^{*}$ & $1,329^{* * *}$ & $-4,820^{*}$ & $4,855^{*}$ & & & \\
\hline
\end{tabular}

Em que: $*=$ significativo a $1 \%$ de probabilidade, $* *=$ significativo a $7 \%$ de probabilidade, $* * *=$ significativo a $20 \%$ de probabilidade; $n s$ = não-significativo; REM = remuneração do exportador; $P R O=$ produção; $U$ = utilização da capacidade instalada; $\mathrm{D}=$ demanda interna; $\mathrm{T}$ = tendência.

A regressão ajustada apresentou um bom poder explicativo, representado pelo alto valor do coeficiente de determinação $\mathrm{R}^{2}$, que mostra um poder explicativo das variáveis independentes de $98 \%$ sobre a oferta para exportação. $O$ teste $F$, de significância global da regressão foi significativo a $1 \%$ de probabilidade. Todos os coeficientes apresentaram os sinais esperados pela teoria econômica e pela literatura.

As variáveis produção (PRO), demanda interna (D) e tendência $(\mathrm{T})$, foram significativas a $1 \%$ de probabilidade. A variável remuneração do exportador (REM) mostrou-se significativa a 7\% de probabilidade e a variável utilização da capacidade instalada (U) foi significativa apenas a $20 \%$ de probabilidade.

Antes de se iniciar as discussões a respeito das elasticidades, é preciso salientar que todos os resultados aqui apresentados são empíricos, e todas as elasticidades são analisadas separadamente, considerando o que em economia se chama de ceteris paribus, e que significa "todo o resto se mantendo constante", o que na prática dificilmente ocorre, sendo a utilização desse tipo de resultado sempre cercado de cuidados em sua utilização prática.

A elasticidade-preço da oferta, representada pela remuneração do exportador, embora significativa, teve um baixo coeficiente, o que indica uma oferta inelástica a preço, como o encontrado por Ângelo (1998) para as madeiras tropicais, o que pode indicar defasagem de ajustamento entre preço e quantidade ofertada, 
ou como sugeriu Brasil (2002), após testar sem sucesso, defasagens nas variáveis relacionadas à remuneração do exportador, se essas séries tivessem periodicidade mensal ou trimestral talvez fosse mais fácil perceber as relações entre preço e quantidade ofertada.

O índice de produção (PRO) indica, para o agregado, uma quase-neutralidade, tendendo para um viés anti-exportação, pois dado um crescimento de $10 \%$ na produção do agregado, as exportações cresceriam apenas $9,3 \%$.

A variável demanda interna (D), construída como a utilizada por Ângelo et al. (1998), apresentou um coeficiente negativo, -1,2 indicando uma tendência de diminuição das exportações no caso de um aumento da demanda não ser acompanhado por aumento na produção. Ângelo et al. (1998) também encontraram um coeficiente negativo para essa variável.

A variável $U$, utilização da capacidade instalada industrial, que mede os ciclos, ou seja, os períodos de baixa e alta atividade da indústria nacional, mostra um viés pró-exportação indicando um aumento de exportações quando a economia se aquece. Um aumento de $10 \%$ nessa variável, ceteris paribus, causaria um aumento das exportações do agregado em torno de $0,5 \%$. Esse resultado é contrário ao encontrado por Raimundo (2001), com madeira serrada de coníferas e painéis, e Brasil (2002) com painéis, contudo, o presente trabalho analisa es exportações de um agregado que foi fortemente influenciado pelas exportações de madeira serrada de não-coníferas.

Segundo Ângelo et al. (1998), a variável T, tenta captar os deslocamentos da curva, nesse caso de oferta, e os efeitos de fatores diversos, que criariam uma tendência anti ou pró-exportação. No presente trabalho, a variável tendência $T$, apresentou um valor menor que a unidade, o que indica uma fraca tendência de aumento das exportações brasileiras com o passar do tempo, Wyzykowski e Almeida (2002), em seu trabalho sobre as exportações brasileiras de manga, também encontraram uma tendência positiva no aumento da oferta para exportação.

A estatística DW de Durbin e Watson, para testar a presença de autocorrelação serial dos resíduos $(\mathrm{DW}=1,87)$, indica inexistência de autocorrelação serial dos resíduos a 1\% de significância.

\section{Demanda}

A equação ajustada para a demanda apresentou um bom poder explicativo, representado pelo alto valor do coeficiente de determinação $\mathrm{R}^{2}$, que mostra um poder explicativo das variáveis independentes de $84 \%$ sobre a demanda de nosso agregado pelos países importadores. O teste $F$, de significância global da regressão foi significativo a $1 \%$ de probabilidade. Todos os coeficientes apresentaram os sinais esperados.

TABELA 2: Estimativa da equação de demanda para as exportações brasileiras de manufaturados de madeira, com dados anuais, no período de 1961 a 2002.

TABLE 2: Estimate of demand equation for the Brazilian exports of manufactured wood, with annual data, from 1961 to 2002.

\begin{tabular}{cc|c|c|c|c|c|c|c}
\hline & Constante & PR & RW & IP & T & $\mathrm{R}^{2}$ & F & DW \\
\hline Coeficiente & $-2,453$ & $-0,302$ & 0,836 & 0,904 & 0,346 & 0,84 & $46,49^{*}$ & 1,73 \\
\hline$t$ & $-4,455^{*}$ & $-1,089^{\text {ns }}$ & $3,567^{*}$ & $2,082^{* *}$ & $0,804^{\text {ns }}$ & & & \\
\hline
\end{tabular}

Em que: $*=$ significativo a $1 \%$ de probabilidade; $* *=$ significativo a $5 \%$ de probabilidade; ns $=$ não-significativo; $\mathrm{PR}=$ preço relativo; $\mathrm{RW}=$ renda mundial; $\mathrm{IP}=$ relação entre produção nacional e mundial; $\mathrm{T}$ = tendência.

A variável renda mundial (RW) se apresentou significativa a $1 \%$ de probabilidade, o índice de participação (IP) foi significativo a $5 \%$ de probabilidade e embora as variáveis preço relativo (PR) e tendência (T) não tenham sido significativas, continuam sendo importantes para o modelo, que apresentou ajustamento satisfatório.

A baixa elasticidade-preço da demanda, relacionada à variável preço relativo (PR), indica uma vantagem para o Brasil, pois aumentos nos preços de nosso agregado em relação aos preços praticados por outros países resultará em pequenas diminuições na quantidade demandada, e aumento do valor das exportações. Isso também pode indicar que os produtos brasileiros são vistos de forma diferenciada pelos importadores, que encontram nos produtos brasileiros, características não-encontradas nos produtos similares ofertados por outros países. Brasil (2002) constatou que as exportações brasileiras de painéis de madeira são 
inelásticas a preço. Raimundo (2001) encontrou para o preço relativo, elasticidades negativas e não significativas para madeira serrada de não-coníferas e painéis, o que confirma os nossos resultados.

A variável renda mundial (RW) apresentou um coeficiente de 0,84 , de forma que um aumento de $10 \%$ na renda mundial, ceteris paribus, levaria a um aumento de aproximadamente $8,4 \%$ na demanda pelo agregado brasileiro. Esse valor indica que o nosso agregado se comporta no mercado internacional como um bem normal. Brasil (2002), encontrou 1,47 para o agregado de painéis, 1,60 para o compensado, 0,76 para os painéis de partícula, 0,43 para os painéis de fibra e 0,87 para os laminados. Raimundo (2001) encontrou 0,84 para madeira serrada de não-coníferas, 0,39 para painéis à base de madeira e 1,13 para madeira serrada de coníferas, esse ultimo, apenas para o período de 1988 a 1999.

O índice de participação (IP), que tenta medir a influência da participação brasileira, como produtor, nas exportações do agregado apresentou um bom resultado, que indica um crescimento da demanda de $9 \%$ para um crescimento relativo de $10 \%$ do Brasil como produtor.

Considerando a diminuição dos estoques florestais no sudeste asiático, o Brasil terá um aumento pela demanda de seus produtos madeireiros. Aliando isso à baixa elasticidade-preço da demanda, o Brasil poderá aumentar os preços de seus produtos madeireiros, de forma a tornar mais rentável a utilização de técnicas de manejo florestal e a certificação. Contudo se deve ter cuidado com o perigo de exploração predatória das reservas florestais, sobretudo as amazônicas, que podem ser causadas pelo aumento dos preços e da demanda.

A variável tendência (T), que tenta captar as mudanças em fatores como gosto e preferência, entre outros demonstra mudanças no comportamento dos países importadores de forma a aumentar a demandar pelos produtos brasileiros com o passar do tempo, embora de forma muito fraca.

A estatística DW de Durbin e Watson, para testar a presença de autocorrelação serial dos resíduos $(\mathrm{DW}=1,73)$, indica inexistência de autocorrelação serial dos resíduos a $1 \%$ de probabilidade.

\section{CONCLUSÕES}

Os modelos estruturais propostos, para a oferta e demanda do agregado, apresentaram um bom poder explicativo.

Os coeficientes das variáveis explicativas utilizadas tanto no modelo de oferta quanto de demanda apresentaram os sinais esperados e valores satisfatórios.

A oferta de exportações apresentou uma resposta positiva em relação à remuneração do exportador, à produção, à utilização da capacidade instalada (ciclos de atividade econômica doméstica) e à tendência, e negativo em relação à demanda interna.

A demanda pelas exportações brasileiras foi positivamente influenciada pela renda mundial, índice de participação e tendência, e negativamente pelo preço relativo.

A elasticidade-preço da demanda foi baixa, isto tem implicações na conservação dos recursos florestais brasileiros, pois os exportadores poderão aumentar os preços, diminuir as quantidades e ainda assim ter um aumento das receitas.

A elasticidade renda da demanda, próximo de um, indica que o agregado brasileiro se comporta como um "bem normal".

A utilização do Índice de Fisher, para agregar os produtos, objeto deste trabalho, possibilitou a análise das funções de oferta e demanda pelas exportações brasileiras de forma satisfatória.

O Brasil tem apresentado uma taxa crescente de produção do agregado, sendo a madeira serrada de não-coníferas o produto mais produzido seguido do compensado e do laminado.

\section{REFERÊNCIAS BIBLIOGRÁFICAS}

ÂNGELO, H. Custo social das exportações brasileiras de madeiras tropicais na floresta amazônica. Revista Árvore, Viçosa, v. 22, n. 4, p. 483-494, 1998.

ÂNGELO, H.; HOSOKAWA, R.T.; BERGER, R. O Brasil no mercado internacional de madeiras tropicais. Revista Árvore, Viçosa, v. 22, n. 4, p. 483-494, 1998. 
ÂNGELO, H.; SILVA, D.A. As exportações brasileiras de mogno (Swietenia macrophilla, King). Revista Árvore, Viçosa, v. 22, n. 1, p. 113-121, 1998.

BRASIL, A.A. As exportações brasileiras de painéis de madeira. 2002. 74p. Dissertação (Mestrado em Ciências Florestais) - Setor de Ciências Agrárias, Universidade Federal do Paraná, Curitiba, 2002.

COCRANE, D.; ORCUTT, G. H. Application of least squares regressions to relationships containing autocorrelated error terms. Journal of the American Statistical Association, v. 44, p. 32-61, 1949.

FOOD AND AGRICULTURE ORGANIZATION OF THE UNITED NATIONS. FAO Statistical Database. Disponível em : < http://www.fao.org >. Acesso em : nov. 2004.

GUJARATI, D. N. Econometria básica. São Paulo : Pearson Education do Brasil, 2000, 846 p.

IPEADATA. Instituto de Pesquisa econômica Aplicada. Título. Disponível em: $<$ http://www.ipeadata.gov.br $>$ Acesso em: nov. 2004.

RAIMUNDO, Y. M. Análise das exportações brasileiras de madeira serrada e painéis à base de madeira no período de 1961 a 1999. 2001. 141p. Dissertação (Mestrado em Economia Aplicada) - Escola Superior de Agricultura Luiz de Queiroz, Piracicaba, 2001.

WYZYKOWSKI, J.; ALMEIDA, C.O. Oferta e demanda de manga brasileira no mercado internacional - 1980 a 1999. Magistra, Cruz das Almas, v. 14, n. 2, p. 115-122, 2002.

ZINI JR, A. A. Funções de exportação e de importação para o Brasil. Pesquisa Planejamento Econômico, Rio de Janeiro, v. 18, n. 3, p. 615-662, 1988. 